\title{
PRODUCTION OF TECHNOLOGY METALS FROM WASTE ELECTRONICS
}

\author{
Maja Mandić ${ }^{*}$, Jovana Đokić2 ${ }^{2}$ Nataša Gajić3 ${ }^{3}$ Jelena Uljarević4, Željko Kamberović ${ }^{5}$ \\ ${ }^{1,5}$ Faculty of Technology and Metallurgy, University of Belgrade \\ ${ }^{2}$ Innovation Center of Faculty of Chemistry in Belgrade Ltd., University of Belgrade \\ ${ }^{3,4}$ Innovation Center of Faculty of Technology and Metallurgy in Belgrade Ltd., University of Belgrade
}

The rising criticality of technologically inevitably metals and the continuous growth of the waste electronics promote a scientific need for development of innovative recycling process, both efficient and selective. Experimental results showed primarily that by pyrometallurgical treatment it is difficult to achieve selectivity, and secondary that the distribution of metals in melting products is too complicated, deviating from the experiential and expected. Therefore, application of an integral pyro - hydrometallurgical treatment is suggested for improved raw materials efficiency. Successful implementation of the developed state-of-art technological process, guarantee more efficient approach to recycling processes, production of new materials which supports the concepts of sustainable development and cleaner production. Proposed technological solution is applicable in industry with relatively low investments compared to expected revenues, allowing companies to become competitive in the regional market and beyond, which is particularly important for small and medium enterprises with lower operating capacities. Techno-economic justification and integral pyro - hydrometallurgical process for waste electronics recycling is presented. This paper explains measures for the further development of the recycling industry as a part of circular economy strategy in Serbia.

Key words: recycling, technology metals, waste electronics, circular economy

\section{INTRODUCTION}

The new consumer society and the rapid development of technology have contributed to shortness of the electrical and electronic devices lifespan (e-devices), making e-devices waste (e-waste) the world's fastest-growing waste stream. The annual growth of e-waste is estimated at 3-4\%, which is why it is expected that by 2021 . the quantity will exceed $52 \mathrm{mt}$ [1]. This is an ongoing problem, but also a golden opportunity having in mind the value of this kind of waste. The most precious part of e-waste is printed circuit boards (WPCBs) as bearers of almost every stable element of the periodic system although the share of individual metals varies depending on the origin, type and manufacturer. The chemical composition of PCBs changed during time: in the 1980s computer chips were made with 12 elements, while today that number exceeds 60 different elements. Many of them are on the EU list of critical materials, making e-waste as an important secondary source and base of urban mining $[2,3]$. E-waste and particulary WPCBs are used to produce base $(\mathrm{Cu}, \mathrm{Ni}, \mathrm{Fe})$, precious metals (PM - Au, Ag, Pd, Pt) and technology metals (TM - In, Ga, Ge) but due to its heterogeneity traditional recycling relying on metal production from primary sources is no longer justifiably [4]. The pyrometallurgical process, although widely used for recycling e-waste, has a low degree of flexibility that does not support the constant change in e-waste composition, high cost, material pre-concentration and off-gas treatment necessity. Hydrometallurgical methods require physical-mechanical pretreatment which increases the process costs and the probability of metal loss. Also, the by-products of classic pyro- and hydrometallurgical treatments, which are the carrier of TM, are most often deposited in landfills, leading to irreversibly metals loss [5].

Nowadays, the traditional concept of linear economic has shifted to a circular model in order to maximize products, components and materials usefulness across the entire lifecycle. Materials from used products are recovered and used in manufacturing new products, reducing the need for primary raw materials. Recycling is essential to the circular economy (Figure 1). Generally speaking, the main goal of the circular economy is to minimize the use of natural resources and to eliminate waste accomplishing zero waste strategy. Current recycling practice is not sufficient for today's economic strategy $[5,6]$.

\section{EXPERIMENTAL}

Materials and methods - Different categories of e-waste magnetic fraction, obtained after physical shredding and magnetic separation were used in this study. Physical characterization included determination of the moisture content by drying the samples at $105{ }^{\circ} \mathrm{C}$ to constant mass, granulometric composition using Retch Vibratory Sieve Shaker AS 200, with a standard set of sieves and bulk density by measuring the mass of three different known volumes of the free coated sample layer.

Chemical characterization was done by combining various instrumental methods (optical emission spectrometry - OES, modified cupellation method and X-ray fluorescence spectrometry - XFR) for detailed analysis and process proposal. Preparation of the sample for analysis 
included the vacuum pyrolysis of $500 \mathrm{~g}$ sample (heating $3 \mathrm{~h}, 150{ }^{\circ} \mathrm{C} / \mathrm{h}$; treatment $1 \mathrm{~h}, 500{ }^{\circ} \mathrm{C}$; cooling $4 \mathrm{~h}$ ) to remove polymeric and other organic compounds (gases, liquids) that could jeopardize the pyrometallurgical process. This is also a step in the pretreatment of the sample for pyro-hydrometallurgical treatment of e-waste. Vacuum pyrolysis solid residue (50-100 g) was further melted with $\mathrm{Cu}$ as a metal collector, (material: $\mathrm{Cu}=1: 1$ ), in order to prepare a sample for the OES analysis and to determine distribution of metals in melting products (metal, slag and filter dust phase). The melting process was carried out in a laboratory scale electric arc furnace, under reduction conditions at $\sim 1550{ }^{\circ} \mathrm{C}$ for $30 \mathrm{~min}$. PM content was determined by modified cupellation method conducted on the depolymerized sample. Process included sample:Pb fusion (mass ratio $1: 10,900{ }^{\circ} \mathrm{C} / 20$ $\min , 1000^{\circ} \mathrm{C} / 20 \mathrm{~min}$ ) to the lead button formation which was further heated at $900{ }^{\circ} \mathrm{C} / 60 \mathrm{~min}$, and $950{ }^{\circ} \mathrm{C}$, until the Dore alloy was formed.

\section{RESULTS AND PROPOSAL OF INTEGRAL PYRO- HYDROMETALLURGICAL PROCESS}

By physical characterization of the sample it was determined that the moisture content is $0.15 \%$ and the bulk density is $1800 \mathrm{~kg} / \mathrm{m} 3$. The granulometric composition shows that $80 \%$ of the material mass consists of particles larger than $2 \mathrm{~mm}, 17.5 \%$ of the mass are $1-2 \mathrm{~mm}$ size particles and that fraction less than $0.5 \mathrm{~mm}$ is only 2.5\% (Figure 2).

The chemical composition of the samples is shown in Table 1.

According to results, investigated material is characterized an extremely complex and heterogeneous in chemical composition. The content of $\mathrm{Fe}$ is dominant, followed by the content of $\mathrm{Cu}, \mathrm{Sn}, \mathrm{Mn}, \mathrm{Ni}$ and $\mathrm{Pb}$. It is determined that the total amount of oxides (refractory materials) is about $30 \%$ off input material. Based on the chemical composition analysis, it was confirmed that investigated material contains TM (In, Ga, Ge, Zr) and PM (Au, Ag), as a direct result of generic origin. Also, traces of $\mathrm{Mo}, \mathrm{Bi}$, $\mathrm{V}$, and Se are identified.

Chemical analysis of the pyrometallurgical products metal, slag and filter dust phase - showed that $\mathrm{Cu}, \mathrm{Cr}$, $\mathrm{Fe}, \mathrm{Mn}, \mathrm{Ni}, \mathrm{Pb}$ and $\mathrm{Sn}$ are scattered between all three phases, while $\mathrm{Ag}, \mathrm{Ti}, \mathrm{Zn}$ and $\mathrm{Zr}$ are divided between slag and filter dust phases (Figure 3). Having in mind the extremely heterogeneous composition of the e-waste sample and the non-selectivity of traditional pyrometallurgical processes, it is necessary to integrate hydrometallurgical methods in order to achieve higher metal valorization efficiency.

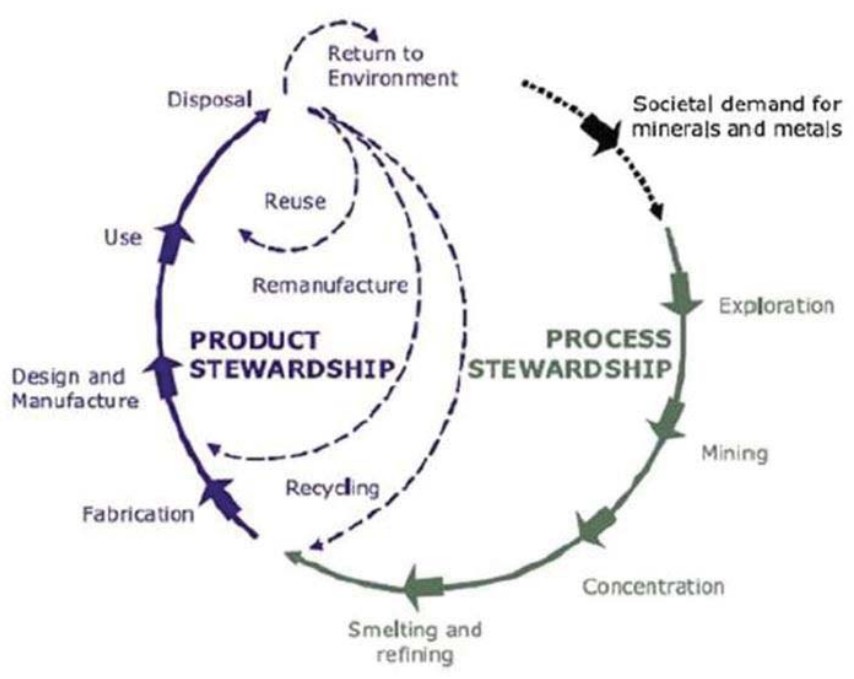

Figure 1: The scope of materials stewardship [6]

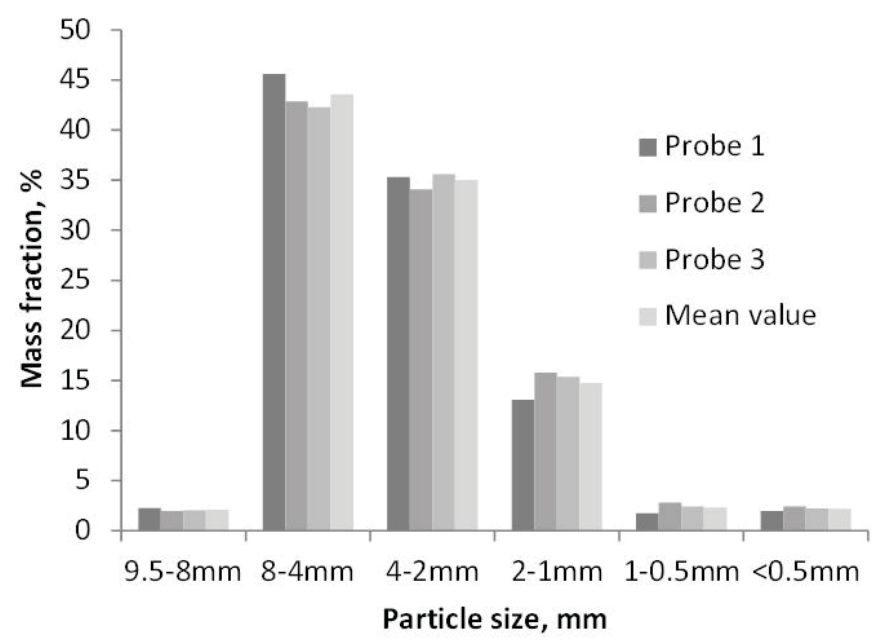

Figure 2: Granulometric composition of the sample

Table 1: Chemical composition of e-waste magnetic fraction, determined by using XRF and OES methods

\begin{tabular}{|c|c|c|c|c|c|c|c|c|c|c|c|}
\hline \multicolumn{10}{|c|}{ Major elements, wt. \% } \\
\hline $\mathrm{Ag}$ & $\mathrm{Cr}$ & $\mathrm{Cu}$ & $\mathrm{Fe}$ & $\mathrm{Ga}$ & $\mathrm{In}$ & $\mathrm{Mn}$ & $\mathrm{Ni}$ & $\mathrm{Pb}$ & $\mathrm{Sn}$ & $\mathrm{Ti}$ & $\mathrm{Zn}$ \\
\hline 0.82 & 1.62 & 7.78 & 44.19 & 0.41 & 0.19 & 3.61 & 3.12 & 2.06 & 3.54 & 0.3 & 1.58 \\
\hline \multicolumn{8}{|c|}{ Minor elements, ppm } \\
\hline $\mathrm{Au}$ & $\mathrm{Ge}$ & \multicolumn{2}{|c|}{$\mathrm{La}$} & \multicolumn{3}{c|}{$\mathrm{Sb}$} & \multicolumn{3}{c|}{$\mathrm{Zr}$} \\
\hline 60 & 160 & \multicolumn{3}{c|}{19} & \multicolumn{3}{c|}{986} \\
\hline
\end{tabular}


Accordingly, vacuum pyrolysis is proposed as a pretreatment in order to i) remove polymeric and other organic compounds, ii) generates energy by the off-gas stream, iii) concentrate metals suitable for further treatment. Smelting of the depolymerized metal concentrate, as an alternative to time-consuming oxygen-enriched air blowing process, allows minimization of PM losses and is identified as ideal for processing of inorganic metal streams arising from gasification/oxidation stage. Further, the hydrometallurgical process is proposed (Figure 4) for the treatment of filter dust (acid leaching followed by solvent extraction/re-extraction) and metal phase (electrowinning), which are products of the proposed pyrometallurgical process. Hydrometallurgical processing of filter dust allows technological metal valorization. Electrolytic refining purifies copper, while further treatment of the by-product (anode slime and tin residue) allows valorization of Sn leading to the PM concentration. Tin free material facilitates the technology of PM valorization.

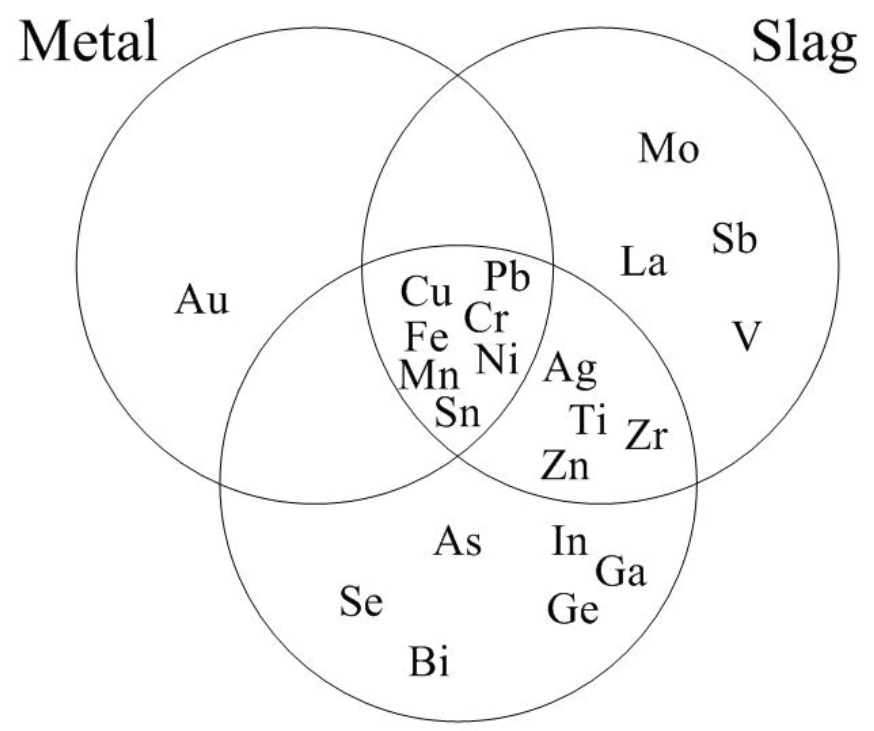

Filter dust

Figure 3: Distribution of metals by phases (metal-slag-filter dust) after EAF smelting

Table 2: A potential value of the material based on certain metal content

\begin{tabular}{|c|c|c|c|c|c|}
\hline Metal & Abundance & \multicolumn{2}{c|}{ Price } & Value, \$/t \\
\hline $\mathrm{Cu}$ & 78 & $\mathrm{Kg} / \mathrm{t}$ & 6.5 & $\$ / \mathrm{kg}$ & 507 \\
\hline $\mathrm{Sn}$ & 35 & $\mathrm{Kg} / \mathrm{t}$ & 21.8 & $\$ / \mathrm{kg}$ & 763 \\
\hline $\mathrm{Ag}$ & 8 & $\mathrm{Kg} / \mathrm{t}$ & 487 & $\$ / \mathrm{kg}$ & 3896 \\
\hline $\mathrm{Ga}$ & 4 & $\mathrm{Kg} / \mathrm{t}$ & 331 & $\$ / \mathrm{kg}$ & 1324 \\
\hline $\mathrm{In}$ & 2 & $\mathrm{Kg} / \mathrm{t}$ & 388 & $\$ / \mathrm{kg}$ & 776 \\
\hline $\mathrm{Ge}$ & 160 & $\mathrm{~g} / \mathrm{t}$ & 2.2 & $\$ / \mathrm{g}$ & 352 \\
\hline $\mathrm{Au}$ & 60 & $\mathrm{~g} / \mathrm{t}$ & 41.3 & $\$ / \mathrm{g}$ & 2478 \\
\hline \multicolumn{7}{|l|}{ Total } & apparent value & 10000 \\
\hline
\end{tabular}

\section{ECONOMIC JUSTIFICATION}

Most often, the choice of a technological solution, allowing the techno-economic justification of the procedure, is based on the Best available techniques document [7]. However, in the case of non-standard material, such as e-waste, it is necessary to apply specific technological process. In order to examine the potential value of the material, which was the subject of this paper, economic valuation based on the current market prices of the selected metals ( $\mathrm{Cu}, \mathrm{TM}$ and PM) was made (Table 2) [8-10].

The value of the material presented in Table 2 is an apparent estimation: on the one hand, it is based on 7 chosen metals identified in the material, and on the other hand it is the assessment carried out without taking into account the material flow chart and capital and operating costs for the metal valorization and process justification.

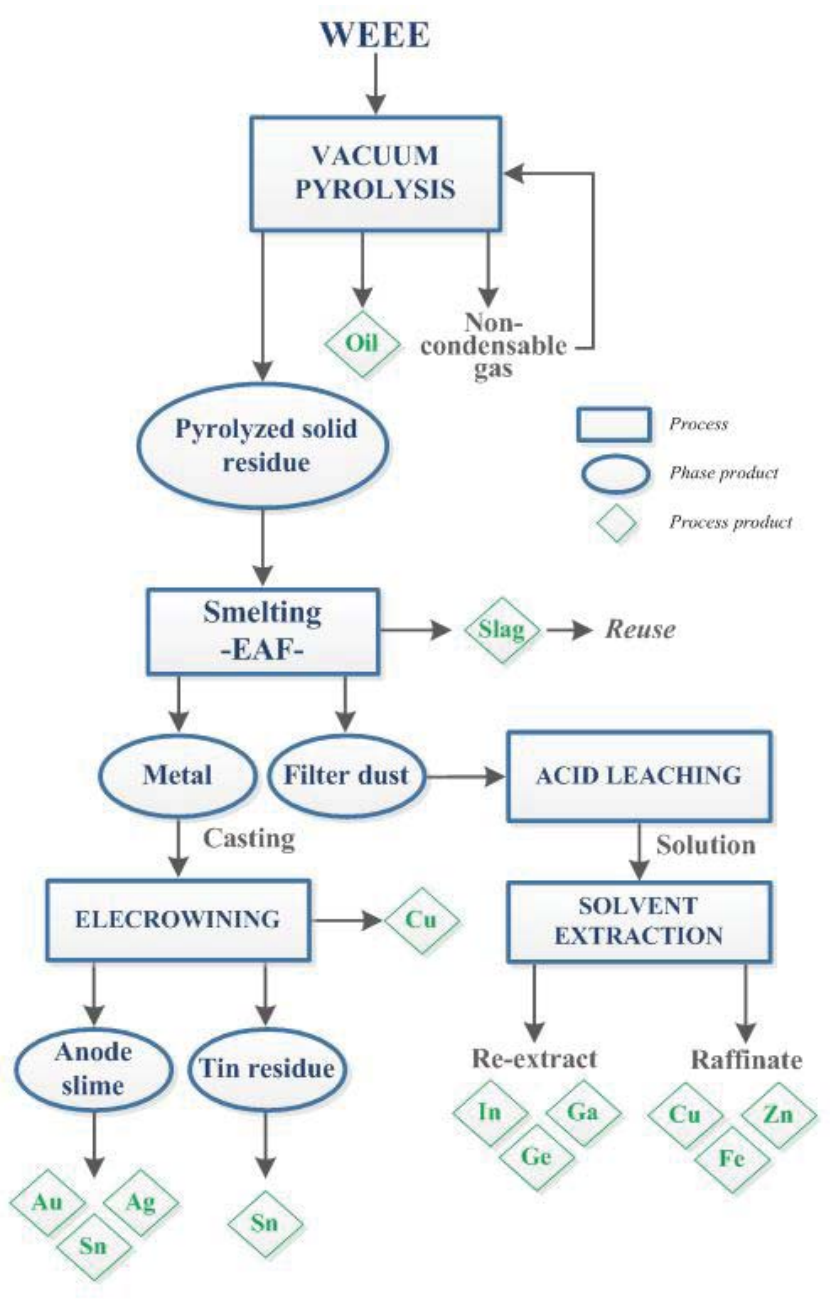

Figure 4: Proposal for the technological scheme for integral pyro-hydrometallurgical TM valorization 


\section{CONCLUSION}

The unsuited disposal of e-waste, as well as insufficient and non-selective valorization of materials due to the lack of adequate recycling procedure, led to the loss of valuable metals. Some of them, like TM that are particularly significant for the modern high-tech industry, have been declared as critical for EU. In order to overcome traditional recycling processes that do not follow the evolution of e-devices, it is necessary to develop a modern, flexible metallurgical recycling process. It has been shown that traditional smelting process results in dissipation of elements between all three phases reducing the valorization possibility. An innovative integrated pyro-hydrometallurgical method for the recovery of both major and minor metals contained in a chemically complex material such as e-waste is proposed in this paper. Besides, economic estimation of investigated e-waste is given. Estimation indicates its great value and gives a guideline for justified valorization in which closed loop production system is achieved.

\section{REFERENCES}

1. Zhang, L., Xu, Z. (2016). A review of current progress of recycling technologies for metals from waste electrical and electronic equipment. Journal of Cleaner Production, vol. 127, 19-36, DOI:10.1016/j. jclepro.2016.04.004

2. Ilankoon, I.M.S.K., Ghorbani, Y., Chong, M.N., Herath, G., Moyo, T., Petersen, J., (2018), E-waste in the international context $-A$ review of trade flows, regulations, hazards, waste management strategies and technologies for value recovery, Waste Management, 82, 258-275.

3. European Commission, (2014). Report on Critical Raw Materials for the EU.

4. J. Cui, J., Zhang, L. (2008). Metallurgical recovery of metals from electronic waste: A review, Journal of Hazardous Materials, vol. 158, 228-256, DOI: 10.1016/j.jhazmat.2008.02.001

5. Worrell, E., Reuter, M. A., (2014). Handbook of recycling: State-of-the-art for practitioner, analysts, and scientists, USA: Elsevier, ISBN: 978-0-12-396459-5
6. Nowakowski, P., Mrówczyńska, B., (2018). Toward sustainable WEEE collection and transportation methods in circular economy - Comparative study for rural and urban settlements, Resources, Conservation \& Recycling, vol 135, 93-107, DOI: 10.1016/j. resconrec.2017.12.016

7. European Commission, (2017). Best Available Techniques (BAT) Reference Document for Waste Treatment, Brussels.

8. KITCO, from https://www.kitco.com/strategic-metals/, accessed on March 6. 2019.

9. GoldPrice, from https://www.goldprice.org, accessed on March 6. 2019.

10. LME, from https://www.Ime.com/Metals/Non-ferrous\#tabIndex=0, accessed on March 6. 2019. 